\title{
El artista de variedades en el Buenos Aires de principios del siglo XX
}

\section{Susana Shirkin \\ GETEA-Universidad de Buenos Aires - Universidad del Salvador, Argentina susashir@hotmail.com}

Fecha de recepción: 30/03/2018. Fecha de aceptación: 07/05/2018.

\begin{abstract}
Resumen
El presente trabajo sostiene la hipótesis de que las características mismas del varieté, la falta de amparo legal que propiciaba la explotación femenina e infantil, la trashumancia que derivaba en imposibilidad de establecer vínculos estables con la sociedad de recepción y de elemental escolaridad en el caso de los menores, el desconocimiento del idioma en los extranjeros, entre otras muchas condiciones, colocaron al artista de variedades de la primera mitad del siglo XX en una situación de vulnerabilidad extrema, lo alejaron de la posibilidad de concretar una organización aún básica y lo vincularon a un circuito de marginalidad social y legal que muy frecuentemente involucraba explotación laboral, prostitución, trata de blancas, abusos y otros delitos penales, ante la mirada al menos indiferente y muchas veces abiertamente hostil de la sociedad de su tiempo que -paradójicamente-conformaba su público.
\end{abstract}

\section{The Variety Artists in Buenos Aires in the Early $20^{\text {th }}$ Century}

\begin{abstract}
This work supports the hypothesis that the characteristics of variety performances -the lack of legal protection that fostered the exploitation of women and children, the transhumance that resulted in the impossibility of establishing stable links with the receiving society and elementary schooling in the case of the minors, the ignorance of the language in foreigners, among many other conditions- placed variety artists of the early 2oth century in a situation of extreme vulnerability, distancing them from the possibility of accomplishing even a basic level of organization and connecting them to a circuit of social and legal marginality that very often involved labor exploitation, prostitution, women trafficking, abuse and other criminal offenses, before the at least indifferent and often openly hostile view of the society of their time that, paradoxically, conformed its public.
\end{abstract}

\section{Palabras clave}

artistas de variedades; condiciones laborales; gremios; legislación; vulnerabilidad

\section{Keywords}

Variety Artists; Labor Conditions; Unions; Legislation; Vulnerability 
La Argentina de las primeras dos décadas del siglo XIX fue escenario de profundos cambios que se potenciaron a partir de la década de 1880: la organización de un orden conservador, la incorporación a los mercados mundiales importando cereales y carnes y la incorporación al país de la inmigración masiva fueron variables decisivas sin que significaran una ruptura completa con períodos anteriores ni que afectaran a todas las regiones por igual

Una de las manifestaciones artísticas que más público atrajo en el Buenos Aires finisecular entre 1890 y 1918 fue el varieté o teatro de variedades que se constituyó, además, en fiel espejo de muchas problemáticas sociales de la época como la inmigración - entre los artistas hubo un altísimo grado de extranjería - la prostitución, la indefensión de la infancia, la cuestión social y la compleja construcción de la identidad del artista de variedades como trabajador en un universo laboral en plena formación y efervescencia

El teatro de variedades comprende una serie de números independientes entre sí, es decir que no guardan relación argumental unos con otros, pero comparten un mismo espacio de representación; una característica fundamental es su cualidad heterogénea.

Raquel Prestigiácomo, mencionando al varieté o variedades de origen francés, lo define como "espectáculo ligero, sin argumento continuo, con carácter preferentemente musical (...) y de representación no teatral sino callejera o tabernera que a mediados del siglo XIX pasa a representarse en el interior del teatro perdiendo así" (1995: 2). Parte de su carácter licencioso pero incorporando en su lugar números de circo como ilusionistas, contorsionistas y acróbatas y atracciones exóticas, como ventrílocuos y hombres-orquesta, para no perder espectacularidad. Prestigiácomo concluye que en el varieté existen tres elementos fundamentales: el número cantable, el bailable y el cómico.

Otro trabajo que reafirma la definición inicial es el de Osvaldo Sosa Cordero (1999), quien pone énfasis en el traspaso a las salas teatrales y al devenir de esta forma teatral, la siendo la competencia entre diversos espectáculos lo que incita a la superación tanto a nivel interpretativo como en el de la representación escénica:

los tabladillos ínfimos del café - cantant o café - concert resultaron ya marcos pobres y rudimentarios para el desempeño de las atracciones que enriquecían sus equipos con decorados vistosos, a menudo mutables, lujoso vestuario $y$, donde eran posibles juegos de luces que jerarquizaban el espectáculo cuya variedad de matices abarcaba el circo, la pantomima, la danza, el canto, el monólogo, la parodia, la bufonada y todo tipo de manifestación escénica breve que escapara a un encasillamiento determinado (1999:39).

De ambos trabajos sobre el teatro de variedades hay para éste, dos cualidades centrales: por un lado, la heterogeneidad de piezas breves que reúnen en cada espectáculo, como por ejemplo números musicales, circenses, animales y celebridades y, por el otro, el énfasis dado a lo espectacular.

Si bien se puede decir que el teatro de variedades opera como estructura modelo, existe por parte de las compañías una apropiación singular relacionada con el público: el elemento licencioso del teatro de variedades queda así anulado dirigiendo los espectáculos a un público netamente familiar. Las familias del Buenos Aires finisecular fueron asiduas asistentes a los espectáculos de varieté ofrecidos por numerosas salas teatrales de la época, entre los que se destacó el teatro Casino, que contaron con un interminable desfile de artistas nacionales, pero sobre todo extranjeros, fruto de una fluida corriente llegada de Europa que - aproximadamente - entre 1900 y 1910 superarían a los locales. 
El Casino, popular teatro de la calle Maipú, fue considerado en la época como la "catedral del varieté". Su empresa estaba pendiente de cuanta novedad extraordinaria surgiera para sorprender a su público; así pasaron por sus escenarios los más prestigiosos números de variedades nacionales y extranjeros. El teatro fue reconstruido con techo corredizo y se emplazaron gran cantidad de ventiladores, lo que le aseguraba una vasta concurrencia en verano, aventajando a otras salas sin estas comodidades; en 1913 funcionaba además una terraza con servicio de bar y se ofrecían vistas gratuitas de cinematógrafo. Sus ganancias sustentaron la sostenida publicidad: la propaganda de sus espectáculos apareció extensamente en los magazines de la época como Caras y Caretas, PBT, Fray Mocho entre muchos otros. Pero al año siguiente -1914 - el panorama internacional cambió abruptamente, ya que el mundo se vio envuelto en un conflicto bélico de una magnitud y extensión inéditas, que afectó profundamente a la sociedad toda y repercutió en el vulnerable mundo del espectáculo.

A juzgar por el espacio que se le dedica en general a la conexión de la Argentina con la I Guerra Mundial, ésta podría haber sido nula, insignificante o, al menos, marginal. Esto no responde a la realidad. La Argentina ocupaba un lugar destacado en el comercio mundial, ya que figuraba entre los mayores clientes y proveedores de las principales naciones del mundo: era abastecedora de productos alimentarios y otras materias primas para los países europeos y estaba vinculada a ellos por estrechos lazos económicos, étnicos y culturales. El estallido bélico coincidió con un especial momento en la historia argentina: el sector mayoritario de las elites conservadoras, que había decidido llevar a cabo una reforma electoral en 1912 que adecuara el sistema político a las transformaciones demográficas y sociales ocurridas, se vio desbordado por el resultado surgido de la misma. Por otra parte, a causa de la conflagración cesaron de entrar importaciones y capitales europeos. El país debió definir su postura de cara a una guerra que enfrentaba entre sí a naciones con las cuales mantenía relaciones amistosas. Los presidentes Victorino de la Plaza e Hipólito Yrigoyen mantuvieron la neutralidad argentina pese a las presiones de las naciones aliadas.

El desencadenamiento de la I Guerra Mundial provocó en el mundo del varieté un impacto decisivo y los artistas tomaban partido: en las funciones se cantaba la Marsellesa. Había una fuerte influencia de la cultura francesa en las elites y en la moda, mientras los usos y costumbres tenían influencia inglesa. Se llevaron a cabo numerosas funciones a beneficio de los beligerantes y el cuadro alegórico se usó como propaganda de todos los contendientes.

El Teatro Casino aprovecha la afluencia de artistas extranjeros para sus funciones de jerarquía, que decaerá después de la guerra: como la bailarina española Elvira Pujol "la Satanela", acróbatas, ventrílocuos, equilibristas, contorsionistas, mimos, bailarines, patinadores, luchadores, esgrimistas, etc.

Si bien el conflicto generó en sus primeras etapas una afluencia de artistas provenientes del viejo continente ante la grave dificultad o, directamente, la imposibilidad de actuar en países involucrados en el conflicto y sus consecuencias - bloqueo, racionamiento riguroso, trastorno de los transportes, etc. - implicó, sobre todo al promediar la guerra, una drástica reducción de la llegada de artistas, dado el peligro de aventurarse en viajes de ultramar atravesando las áreas de hostilidades de ambos bandos. Con la incorporación a la conflagración de un arma naval novedosa y casi experimental -el submarino- el peligro se potenció. El consiguiente incremento de oportunidades laborales para los artistas locales entre 1914 y 1918 no significaría sin embargo para éstos ninguna mejora salarial ni de condiciones de trabajo: continuó la sujeción a la voluntad del empresario, la modalidad de contratos de palabra, la obligación de proveerse su propio vestuario y accesorios, las multas ante faltas reales o supuestas aplicadas sobre sueldos inferiores muchas veces al salario mínimo de 
la época, la carencia total de algún tipo de cobertura médica -especialmente ante los frecuentes accidentes en escena dada las características de las performances del varieté. A esto se agregaban las penurias de la típica trashumancia que impedía desde la escolarización de los menores hasta la construcción de vínculos de sociabilidad y no era raro el abandono de los artistas, por parte del empresario, en puntos remotos de las giras, sin recursos para regresar.

\section{¿“María de la Cruz" artista o María García Bordadora?}

Ante la falta de registros y la escasez de documentación, la historia oral resulta una herramienta funcional -siempre considerando las características y subjetividades de este recurso- para la reconstrucción del pasado del varieté. Las entrevistas realizadas a la señora María García en 2013 sobre la historia de vida de su madre y de su abuela -también llamadas María García- permiten una aproximación a las condiciones laborales del artista de variedades en el Buenos Aires de la última década del siglo XIX y de las primeras del siglo XX. También contribuyen a conocer algo más sobre cómo aquellos intérpretes se veían a sí mismos y a su arte, y al rol que ocupaban en la sociedad.

En 1897 llegaba de su Galicia natal María García ${ }^{1}$ de 17 años, quién escapando de la pobreza y el maltrato, se había unido a una troupe de cómicos, equilibristas, un ventrílocuo y un transformista, como bailarina, cantante y hasta muñeca del ventrílocuo bajo el nombre artístico de "María de la Cruz". A pesar de su ingreso al mundo de las variedades, María nunca dejó de ejercer de manera informal -sin ningún tipo de agremiación, recibos o profesionalización de ninguna clase- el oficio de bordadora, que aprendiera desde su infancia en Galicia de su madre y su abuela, ambas bordadoras profesionales.

María realizaba para sobrevivir -ante lo magro de sus ganancias como artista- trabajos de bordado en lentejuelas y pedrería en trajes de escena para sus colegas de escenario, así como para ropa de fiesta, lencería y blanco y ajuares de novia para esposas e hijas del personal administrativo y técnico del teatro, por los cuales se le pagaba, pese a su probada habilidad, menos que a una bordadora profesional -que en la época ganaba \$1 diario si era medio oficiala y de 1,50 a \$2, si era oficiala, siendo uno de los trabajos peor remunerados de la industria de la indumentaria (Mundo Argentino, IX (457), 13 de octubre de 1919)- dado que ella era únicamente artista.

En 1913, María García bordó con lentejuelas una levita roja usada en escena por "Mr. Havemann" -célebre domador de fieras de la época- que se presentó en el Casino con leones, tigres y leopardos. En el número de Fray Mocho correspondiente al 19 diciembre de ese año se puede ver una fotografía del domador inglés con un tigre de bengala en su espalda en las instalaciones del teatro.

Pese a pasar largos períodos sin trabajo en las tablas, sobreviviendo ella y su hija llamada también María -a los 18 años había quedado embarazada de otro artista trashumante de origen austríaco, al que nunca volvió a ver-, del producto de su actividad extra de bordadora, jamás accedió a profesionalizarse como tal, considerando que aquel trabajo manual desmerecería su calidad de artista.

La única vez que María fue registrada de alguna manera relacionada a su actuación en los escenarios porteños sería en el censo de la ciudad de Buenos Aires de $1904^{2}$, donde declaró ser artista sin especificar género y quedó incluida entre las doscientas sesenta y seis mujeres extranjeras definidas como "Artistas Teatrales", que superaban con creces a las cincuenta y dos argentinas del mismo rubro. Pese a existir la
1. Agradezco a la señora María García (nieta), sus recuerdos y el acceso a diarios personales y papeles de su madre y su abuela, ambas del mismo nombre. Las entrevistas fueron realizadas en 2013 poco antes de su fallecimiento a los 78 años.

2. Censo General de Población, Edificación, Comercio e Industrias de la Ciudad de Buenos Aires, Compañía Sud Americana de Billetes de Banco, Buenos Aires, 1905. 
distinción entre argentinos y extranjeros, varones y mujeres, la generalización artistas teatrales impide determinar el número real de los dedicados a las variedades en el Buenos Aires de principios del siglo XX.

Un incidente policial en 1919 -revelador de la mirada de la sociedad de la época sobre las mujeres del escenario y reflejada en las instituciones- estigmatiza a María: a raíz de una disputa con otra colega, una contorsionista de origen belga, se origina una pelea -ambas todavía maquilladas y vestidas con trajes de escena- que termina con las dos rivales tomándose del cabello en la vereda del Teatro Casino. $\mathrm{Al}$ intervenir la policía, María fue detenida mientras que la contorsionista lograba huir. Pese a ser claramente un caso de "riña en la vía pública" y haberlo presenciado al menos diez testigos, fue caratulado como "ejercicio de la prostitución", nada más alconstatarse que se trataba de una artista-sobre todo de variedades, de peor fama en la época que las actrices teatrales, según se dijo en la comisaría- vestida y maquillada como tal.

Según el relato de su nieta -de su mismo nombre y apellido al ser, al igual que su madre hija extramatrimonial- su abuela afirmaba que tal situación era usual en las décadas del diez y del veinte del siglo XX: la asociación automática de las mujeres del espectáculo a la prostitución, tanto por las autoridades como por el público en general, por la única razón de su métier. En el Anuario Estadístico de la Ciudad de Buenos Aires (1913) correspondiente a los años 1910 y 1911, la estadística referida a la profesión de las presas en el Asilo Correccional de Mujeres muestra a únicamente dos artistas en 1910 y ninguna en 1911, mientras que constan como prostitutas veinte mujeres en 1910 y cuarenta en 1911. A la luz de lo anterior, no sería aventurado suponer que más de una artista de variedades -ante numerosos incidentes generados dentro y fuera del teatro- hubiera terminado prontuariada como prostituta gracias al prejuicio instalado en la sociedad de la época.

La asociación del mundo del espectáculo en general y del varieté en particular a la prostitución o trata de blancas (como se lo denominaba en la época) era constante y -en muchos casos- verdadera: el compositor Enrique Cadícamo relata en sus memorias la existencia en Buenos Aires de una organización del hampa, cuyos jefes actuaban en Marsella bajo la pantalla de una Agencia Internacional de Negocios Artísticos para América Latina, tratándose en realidad de una organización internacional de tratantes de blancas. Sus organizadores eran los cuatro hermanos Lombard, corsos, dos afincados en Marsella y dos, en Buenos Aires, donde un empresario francés adinerado -Charles Seguin ${ }^{3}$ o "don Carlos"- era el dueño de las salas donde iba a actuar la "mercadería enviada desde Europa por los Lombard" (Szwarcer, 2014).

Charles Seguin estaba vinculado -además de a muchos otros emprendimientos en la Argentina- a la Sociedad Teatral Ítalo-Argentina y regenteaba el Teatro Circo Coliseo Argentino, el Teatro Casino (considerado gran Music Hall de Sudamérica), el Ópera, el Odeón, el Excélsior, el Porteño y el Maipo, entre otros; controlaba lugares clásicos de recreación como el "Pabellón de las Rosas", espacio de diversión y citas galantes, el "Armenonville", sitio clásico de la noche porteña, el Parque Japonés, obra monumental con un gran jardín para el entretenimiento, el Circo Hippodrome, el Cabaret Royal Pigall, el Casino Pigall, el Palais de Glace, inaugurado como pista de patinaje y devenido en salón de baile, el Tabaris, el Chantecler, etc. Expandió sus intereses a circos, teatros, cafés concerts, Cabarets, parques de diversiones, espectáculos de boxeo y lucha libre. En el circo Hippodrome, ubicado en Carlos Pellegrini y Corrientes, llevó como atracción a las "Tribus de Indios" Chiriguanos y Chamacocos, a modo de zoo humano, siguiendo la degradante moda europea que consideraba exótico este tipo de espectáculo. Las afirmaciones de Cadícamo sobre los dichos del bandoneonista Juan Canaro, involucrarían directamente a Charles Seguin en actividades prostibularias
3. Charle Seguin había nacido en Bienne, Suiza, el 28 de enero de 1877. Llegó a la Argentina a los 15 años procedente de Francia. Figura enigmática, con fama de playboy internacional, desde sus comienzos se vinculó con el ambiente artístico y la noche, se convirtió en dueño de un gran imperio económico de distintos rubros, entre 1900 y 1915 . Falleció en alta mar a bordo del Lutetia, rumbo a Europa, el 30 de marzo de 1930. 
a nivel internacional a comienzos del siglo XX. Aunque, como correctamente afirma Szwarcer (2014), faltaría una exhaustiva investigación para llegar a conclusiones definitivas al respecto.

También otras actividades eran frecuentes en artistas del varieté para asegurarse la supervivencia, sobre todo si se tenían hijos que mantener en las precarias condiciones que conllevaba esta profesión. Si bien tanto María García como su hija -también dedicada a las variedades y bordadora como su madre- trabajaron siempre bordando para complementar los paupérrimos ingresos de su actividad en teatros de poca monta, tablados, centros sociales, números vivos en el naciente cinematógrafo y hasta en cantinas y fondas, jamás se profesionalizaron: no se afiliaron al sindicato y siempre consideraron el bordado como una actividad menor, asociada a la supervivencia lisa y llana, y menoscabante de su condición de artistas -aun cuando la ejercían en largos períodos sin trabajo en el escenario- pese a las ventajas que podría haberles deparado.

Según el relato de la entrevistada, esta mirada sobre sí mismo del artista del varieté no era poco frecuente, viéndose ajeno a la condición del trabajador común y portando un don y un rol especiales que lo ubicaba en otro lugar en la sociedad, pese a penurias materiales, el rechazo y a menudo, la marginación. Esta actitud condice con lo sostenido por Mauro (2015), recordando que la condena al usufructo de la actividad artística procede directamente del mundo griego, en el que ciertas prácticas artísticas o deportivas, eran toleradas sólo si el ciudadano renunciaba a la utilidad que pudieran reportar las mismas, o sea, si renunciaba a la posibilidad de ganar su sustento mediante dicha práctica y destaca la pervivencia de esta concepción del artista en la visión dominante en el mundo de la cultura y las artes en la sociedad occidental. Pese a concretarse una asociación en 1918, gran cantidad de artistas permanecieron fuera de la afiliación, sobre todo los extranjeros que, aún decidida la permanencia en el país, no regularizaban su situación legal, no hablaban el idioma como para informarse o no estaban interesados en pagar la cuota societaria

"María de la Cruz" o María García jamás se afilió a las distintas versiones del gremio de variedades existentes a través de los años ni participó en huelgas junto a otros trabajadores del espectáculo, como la de la Federación Gente de Teatro -en 1921- a la que adhirió la Sociedad Argentina de Variedades y Circo, por lo que invitó a sus afiliados a no actuar en los teatros en conflicto.

\section{La dramática situación de los artistas infantiles en el varieté}

En los espectáculos de variedades de las dos primeras décadas del siglo XX porteño, ya comprobable en las dos últimas del siglo XIX, la infancia tenía una presencia habitual y visible. Eran frecuentes, los niños y niñas disfrazados de pequeños payasos, querubines, duendes, aves, cantando, bailando, recitando, realizando acrobacias, avanzando en pequeñas bicicletas sobre alambres, interviniendo en números de prestidigitación- en innumerables funciones diarias comenzando a veces al mediodía, con apenas interrupciones, hasta la medianoche.

Otro significativo aspecto de la falta de control y peligros que se cernían sobre los menores en las variedades era-directamente relacionado con la típica trashumancia de la actividad- la frecuencia con que se incorporaban a sus circuitos niños y adolescentes en situación de vulnerabilidad y riesgo, en muchos casos fugados de sus hogares y en otros, vendidos por sus propios padres. Más de una vez caían en un estado de servidumbre de hecho de cirqueros y empresarios, explotados laboral y sexualmente, a lo que contribuía el aislamiento del menor del mundo exterior a causa de los interminables viajes y la ausencia de vínculos y arraigo. 
La presencia de los niños artistas en los escenarios del Buenos Aires fue profusamente registrada en los magazines de la época como Caras y Caretas, Fray Mocho, PBT y otros. Sin embargo, al tratarse de magazines donde el énfasis estaba puesto en la imagen y no en el texto, la información era mínima y generalmente se limitaba a consignar el nombre del teatro o centro social donde se realizaba la función. Una situación paradójica se puede apreciar en la defensa del canillita -el niño vendedor de diarios-y su situación, reflejada en dichas publicaciones entre 1900 y 1920, a cuyo beneficio se llevaron a cabo funciones en teatros porteños y, al mismo tiempo, la total invisibilidad de la dramática situación de los artistas infantiles que actuaban en esos mismos escenarios.

Numerosos niños de pocos años intervenían en todo tipo de números de variedades como también como complemento y muchas veces como protagonistas de espectáculos circenses, desde los desarrollados en precarias carpas en los barrios o en las provincias hasta en aquellos de la jerarquía de los del célebre Frank Brown, como acreditaba La Nación del 30 de junio de 1897, señalando que el espectáculo del payaso inglés "se ha llevado a la escena por medio de personajes en miniatura, pues solo actúan niños de corta edad".

Sin horarios apropiados para su edad, muchas veces sobre exigidos físicamente por el entrenamiento para los actos en los que se los hacía participar-como en el caso de los pequeños trapecistas o equilibristas o los niños jinetes de ponis enanos- sumado a la habitual trashumancia de su trabajo, hacía imposible para estos niños, no solamente una escolaridad normal, sino muchas veces una mínima integración social y hasta lingüística.

Un amplio número de niños artistas de variedades no estaban alfabetizados, ya que, en la mayoría de los casos, no solían concurrir regularmente a la escuela y no necesitaban memorizar largos parlamentos como en el caso de los actores, lo que se unía al hecho de que muchos de ellos eran extranjeros hijos tanto de artistas en gira por estas tierras o bien de inmigrantes quienes, aún ya decidida su permanencia, todavía se expresaban únicamente en su lengua materna al carecer de una integración social y escolar apropiada.

En las primeras décadas del siglo XX porteño, se pueden detectar numerosos casos de trabajo de niños en espectáculos de variedades que hoy rozarían el maltrato y el abuso infantil, y otros que decididamente lo configuraban plenamente. Tal es el caso del "Niño Bala", que terminó con la muerte por fractura de cráneo del infante de dos años disparado desde un cañón acondicionado para tal fin en un espectáculo con números circenses y musicales en un centro social de Boedo, en 1904. Este episodio es conocido por su constancia en el diario personal de una ocasional espectadora, sin que se registrara en la prensa de la época. ${ }^{4}$ Estas situaciones, pese a ser conocidas y presenciadas por numeroso público, generalmente pasaban casi inadvertidas y rara vez eran registradas por la prensa, ni siquiera en la sección policial del diario.

Una triste y casi única excepción a la invisibilidad de la situación de indefensión y maltrato que padecían muchos niños puede hallarse en diario El Nacional del viernes 2 de octubre de 1908, bajo el título de "La niña araña. Espectáculo inhumano" donde el cronista relataba:

Hemos presenciado ayer un espectáculo abominable, que ya hemos censurado varias veces en vano, inmoral e inhumano que lejos de educar, pervierte y provoca un sentimiento de repugnancia hacia el autor y de compasión hacia la pobre e inocente víctima. Se trata de la explotación escandalosa y criminal de una criatura de 10 años que encerrada en una caja en forma de araña, se exhibe a la malsana curiosidad del
4. Agradezco a Mariana Spratt el acceso a los diarios y recuerdos de su abuela, testigo del hecho. 
público en un salón de Cabildo y Olazábal propiedad de un centro de Socorros Mutuos. ¡Qué fácil es para esos charlatanes sin escrúpulos fomentar la curiosidad malsana del vulgo cuanto más horrorosos son! Se anuncia la exhibición de un sensacional fenómeno "La niña araña”, que no es más que una débil chicuela cruelmente encerrada en un cajón velludo con patas del que solo emerge la infantil cabecita de la víctima dando así la sensación de un colosal arácnido, instalado en mitad del escenario, mientras supuestos actores disfrazados de damas fingen horrorizarse y desmayarse a su alrededor. En esa posición se encuentra la pobre infeliz desde la 1 de la tarde hasta las 12 de la noche iy que tan repelente espectáculo se ofrezca a una cuadra de la comisaría! Consentimos el ejercicio de esos errabundos saltimbanquis bailando sobre un alambre o haciendo prodigios sobre el trapecio aunque entrañe peligro para el ejecutante pero este espectáculo, que provoca indignación en los hombres de bien, no puede tolerarse, so pena de que en pleno siglo XX y en medio de nuestro progreso y cultura se nos lance, con razón, el anatema de salvajes. Esperamos que la autoridad intervenga prohibiendo este espectáculo inhumano (“La niña araña. Espectáculo inhumano", El Nacional, 2 de octubre de 1908).

Del resultado de la preocupación del cronista por la prohibición de aquella atracción vergonzosa, no hay registros.

Otro ejemplo de la peligrosa situación de los menores se halla en la presencia en el circuito circense y del varieté desde 1910 , de Franciska Ottens o Offens, una niña de 15 años, "alemana o austríaca" con poco dominio del castellano, que ayudaba en cuanta tarea se relacionara con las funciones: vestuario, zapatos, limpieza del escenario o pista y todo tipo de recado o diligencia que actores o empresarios le encargaran, durmiendo en camarines y viajando con los artistas en numerosas giras, hasta desaparecer en 1913 sin explicación en la provincia de Salta, presumiblemente rumbo a Bolivia con otra troupe de "saltimbanquis". De la revisión de las Órdenes del día de la Policía de la Capital de la década del diez, puede leerse en la Orden de Captura del 5 de enero de 1910:

El Jefe de Policía ordena la captura de la menor Franciska Ottens, alemana de 14 años, pelo rubio, ojos celeste claro, estatura regular, por haber fugado de casa de sus guardadores, se cree que para unirse a "saltimbanquis" en tránsito y solicitarlo el Señor Defensor de Menores Dr. Pedro de Elizalde (Orden del Día Policía de la Capital. República Argentina. Pedidos de Captura, volumen XXIX, año 1910, T.I).

Los padecimientos y explotación del niño artista fueron sistemáticamente ignorados o tolerados no solo por la prensa sino también por las autoridades, pese a ocurrir a ojos vistas de gran cantidad de testigos y fueron son pocas veces revelados en biografías, relatos o entrevistas a las víctimas en su edad adulta. Del mismo modo, cualquier referencia a la atención médica en general y, sobre todo, en caso de accidentes en escena, es prácticamente inexistente antes de 1918.

Un caso paradigmático -dado a conocer por el mismo protagonista muchos años después- sería el del luego conocido actor cómico Pepe Biondi quién -nacido en 1909 - fuera entregado por sus padres a los 7 años al payaso "Chocolate" (cuyo verdadero nombre fue Juan Bonamorte, nacido en Brasil) Miembro del circo Anselmi, y uno de los más prestigiosos de la época, "Chocolate" entrenó al niño en acrobacias a fuerza de palizas, humillaciones y privación de alimentos, permaneciendo analfabeto hasta los 16 años, cuando aprendió a leer y escribir por sus propios medios y terminó huyendo del circo (La Nación, 4 de octubre de 2004).

Otro aspecto aberrante de la explotación de la infancia en los escenarios del varieté lo constituyeron numerosas criaturas con distintas discapacidades que eran exhibidos 
en circos y espectáculos de todo tipo -desde números vivos consistentes en la simple exposición del menor a la vista del público, hasta danzas y contorsiones que resaltaban su discapacidad - excluidos de la más elemental atención médica y de la escolaridad. Estos niños eran frecuentemente parte de largas giras por pueblos y provincias del interior, impidiendo esta trashumancia no solo que autoridades y gente de bien de la época se interesaran concretamente por su suerte, sino que se investigara la -casi habitual- compra de estas criaturas por empresarios y cirqueros. Uno de tantos casos fue el niño de 6 años -nacido sin brazos- que era exhibido en el circo Raffetto entre 1910 y, por lo menos, 1913, al que se le hacía bailar, servir de blanco humano y caminar sobre el alambre, y que acompañó las giras del circo por el norte del país (el diario El Cívico de Salta publicaba en julio de 1910 noticias sobre las funciones del Politeama Raffetto en el NOA).

\section{Gremio: el largo camino y la lucha inacabada}

Pese a las duras circunstancias que atravesaban, no han podido hallarse registros anteriores a 1918 de intentos serios de agremiación o de organizar una sociedad de socorros mutuos, como ya poseían a principio de siglo numerosos trabajadores desde la década de 1890 -como tipógrafos, almaceneros, policías y bomberos, talabarteros, telegrafistas, empleados municipales, prácticos del puerto, etc. ${ }^{5}$ que obtenían protección en caso de enfermedad y accidente y la cobertura de funerales. La Razón del 26 de julio de 1918 deja constancia de la fundación de una Sociedad Internacional de Artistas de Variedades de socorros mutuos, que -en base a testimonios orales- se podría especular paralela a la Asociación Argentina de Variedades y Circ,o resultado de una asamblea de ciento veinte personas, entre las cuáles se contaron reconocidos nombres de la época como la tiple española "La Goya". Carlos Gardel recibió el carnet No 8 de socio fundador (Seibel, 2011).

Pese a concretarse una asociación en 1918, gran cantidad de artistas permanecieron fuera de la afiliación, sobre todo los extranjeros que, como señalamos, aún decidida la permanencia en el país, no regularizaban su situación legal, no hablaban el idioma como para informarse o no estaban interesados en pagar la cuota societaria. Baste decir que los que adhirieron a la huelga de los actores de 1919, desfilaron por las calles cantando la Marsellesa (Kogan, 2012:34). La carencia de registros no permite precisar cifras concretas de afiliados, certezas en cuanto al desarrollo de la acción sindical o mejoras especificas respecto de los problemas acuciantes del artista de varieté de aquella época.

Pese a exceder los límites de este trabajo, un breve panorama del siglo XX recuerda que en los años 30 funcionó la Unión Argentina Artistas de Variedades. La propia María García compró en 1936 un número de la rifa organizada por la asociación a favor de sus afiliados (se sorteaba por la Lotería Nacional y el primer premio era un coche último modelo de la época y le seguían muebles, máquinas de escribir y de coser).

Pero fue el sindicato fundado en 1951 el que logra afiliar a los más reconocidos artistas de la época y contar con obra social propia. La era peronista traerá -en el contexto de la popularización del nacionalismo cultural, y de la preocupación del gobierno por la difusión de ese acervo cultural nacional y de la promoción del sindicalismo- una de las contadas victorias del artista de variedades sobre la precariedad laboral: la promulgación el 28 de agosto de 1953 de la Ley 14.226, ley del "acto vivo en las salas cinematográficas", al reconocerse la subsistencia de la desocupación que castigaba especialmente al mundo del espectáculo. La Ley brindaría promoción y apoyo a más de cincuenta mil trabajadores. La medida fue apoyada con un concurrido acto en la Plaza de los Dos Congresos por la Unión Argentina de Artistas de Variedades (UADAV),
5. Según el Censo General de Población, Edificación, Comercio e Industrias de la Ciudad de Buenos Aires, Compañía Sudamericana de Billetes de Banco, Bs. As. 1905. 
fundada por el autor y cantante Lito Bayardo junto a José Razzano y Charlo (Carlos José Pérez). Cabe destacar que su sede, sita en Sarmiento 2058, fue adquirida en 1954 y en su escritura constaba la firma de Juan Domingo Perón.

La Ley del Número Vivo implementaba la presentación en las salas cinematográficas del centro y los barrios, durante los intervalos, de un acto de corta duración a cargo de diversos artistas pertenecientes a la Unión Argentina de Artistas de Variedades: canto, magia, ejecución de variados instrumentos, recitado, malabarismo, ventriloquía, danza, etc. La nómina de los intérpretes podía encontrarse en los programas cinematográficos. Esta nueva oportunidad de trabajo, no solo permitía paliar en alguna medida la crónica precariedad económica del gremio sino también darse a conocer al gran público. Estas cortas actuaciones fueron llevadas a cabo no solamente por artistas poco conocidos, sino que se pudo acceder a presentaciones en los cines céntricos de grandes figuras y orquestas -como Osvaldo Pugliese en el Ópera, en enero de 1961- y a actuaciones en los cines barriales de principiantes y consagrados, como las todavía recordadas en el Febo de Jonte y Segurola, el Edison de Liniers, el Sol de Mayo de Villa del Parque, etc.

Otra victoria poco común fue el fallo de la Corte Suprema de Justicia de la Nación del 22 de junio de 1960 ante un conflicto suscitado por la aplicación de la Ley del Número Vivo (Hechos y Fallo de la Corte Suprema de Justicia, 22/6/1960:121 y Ss.). El Legislativo había instituido aquella norma como "un sistema especial destinado a promover la ocupación en lo concerniente a los trabajadores del espectáculo público" en tanto que la actora - el cine Callao - planteaba que se le estaba imponiendo una obligación de contratar en condiciones violatorias de la libertad de comerciar, además de la carga que se imponía al demandarle "la realización de gastos e inversiones no susceptibles de amortización ni rédito". El dictamen del Procurador Dr. Sebastián Soler-quién fuera una reconocida figura en el ámbito jurídico y universitario- entendió que esa exigencia era anticonstitucional en tanto consagraba para una categoría de personas un verdadero privilegio, cuya repercusión económica incide perjudicialmente sobre otra. También se observó que el Estado no resolvía el problema con recursos propios, sino que hacía caer la solución en una categoría de particulares, afectando los derechos con que la Constitución los protege: "el negocio se traduce en realidad en la obligación de prestar un beneficio cuya erogación se pone solamente a cargo de otro sector de la colectividad, determinado y reducido, en vez de ser extensiva, equitativa proporcionalmente a todos los miembros de la comunidad".

Pese a los argumentos en contra, la Corte Suprema resolvió que la ley era constitucional: la obligación tenía un alcance muy limitado, en condiciones que hacían amortizable la inversión, por lo que la carga impuesta a los empresarios "no suprime ni altera el derecho a ejercer su comercio especifico en la sala designada a ese efecto" pudiendo explotarse en las horas y condiciones habituales, señalando además que la Ley cuestionada, lejos de consistir el provecho de un grupo de personas obtenido merced al sacrificio patrimonial de otro grupo, reviste el carácter inequívocamente público o general ya que tiende simultáneamente a "asegurar la defensa del patrimonio artístico nacional". Por todo lo cual, se intimaba al cine Callao a iniciar en el plazo de diez días la presentación de números vivos en la sala bajo apercibimiento de las correspondientes sanciones. La resolución fue mantenida pese a los recursos interpuestos por la firma interesada.

Pese a esta inesperada victoria jurídica en la Corte Suprema, con el correr del tiempo y los cambios políticos, esta fuente de trabajo para el gremio también desaparecería, sobre todo, después que la Revolución Libertadora derrocara en 1955 al gobierno peronista. El número vivo sobrevivió hasta por lo menos la mitad de la década del sesenta en los cines de barrio, que muchas veces no contaban con las instalaciones 
apropiadas para actuaciones en vivo, dejando gratos recuerdos -como las del popular Juan Verdaguer- en aquella generación. Al languidecer y extinguirse esta fuente de trabajo también se perjudicó al público: sobre todo el que por razones económicas o culturales estaba alejado de las funciones teatrales, al perder la oportunidad de ver en vivo a los artistas -desde ventrílocuos y malabaristas a músicos y bailarines- que representaban los más variados matices del espectáculo de variedades.

El tiempo pasa sin que la vulnerabilidad del sector mejore y en la década del 90 la lucha de los artistas de variedades sufre un revés al quebrar el sindicato, entrando en un período de inactividad para resurgir en 2012, después de veinte años. Recuperando su personería jurídica, nucleando a cantantes, bailarines, artistas de circo, animadores y otros rubros vinculados al arte y otorgando distintos beneficios entre ellos, el servicio de prepaga con cobertura nacional y las facilidades legales para la defensa de los artistas, además de la incorporación de nuevos rubros.

\section{Conclusiones}

El vigoroso desarrollo del teatro en Buenos Aires entre 1890 y 1918 no fue acompañado, sin embargo, por una mejora siquiera mínima de las penosas condiciones laborales de los actores en general y de variedades en especial: el agotador número de funciones diarias, el recambio constante de espectáculos, ensayos no remunerados, inexistencia de licencias por accidentes de trabajo, enfermedad, jornadas de descanso o jubilación. También una condena social difusa por parte del público -pese a concurrir como espectadores a sus espectáculos- y concreta de parte de instituciones como la Iglesia, la Policía, organizaciones de derecha como la Liga Patriótica y distintas publicaciones.

La actividad teatral estaba supeditada -ante la falta de legislación laboral y la ausencia de políticas en la materia- a la voluntad del empresario de sala que en el caso de las variedades, dada la especificidad propia del género traducida en la renovación constante de actos y protagonistas, la heterogeneidad de estos -desde tonadilleras, bailarinas y contorsionistas hasta ventrílocuos, tragasables, domadores de fieras y hombres elásticos- la trashumancia de las giras y la extranjería abrumadora de los artistas entre 1890 y 1914, con frecuencia ligaban la actividad al ámbito delictual: prostitución, explotación, abuso y secuestro de menores, reducción a la servidumbre. Todo lo cual contribuyó a que los artistas no fuesen vistos como trabajadores.

El teatro de aquellos años de la segunda mitad del siglo XIX y las primeras décadas del XX tuvo una concreta vinculación a la prostitución -baste recordar los remates de mujeres en el Teatro Alcázar en la década porteña de 1870- que quedaría profundamente internalizada por la sociedad hasta casi la actualidad, aunque en nuestros días se la relacione más específicamente con el género revisteril. En aquel período autoridades y sociedad, habiendo incorporado en muchos casos la asociación automática entre el mundo del espectáculo y el delito, contribuyeron al aislamiento y marginación del artista de variedades, visto con desconfianza cuando llegaba con su espectáculo a -especialmente- pueblos y ciudades pequeñas.

En muchos casos los artistas, llamados muchas veces despectivamente saltimbanquis, permanecían al margen de toda legislación con la que -como ciudadanos argentinos, extranjeros en tránsito o inmigrantes radicados en el país-el Estado protegía a quienes habitaban su territorio: no solamente porque las autoridades encargadas de hacerla cumplir los percibían automáticamente como gente peligrosa y de mal vivir, sino por su propia auto-marginación. 
A la mínima identificación del artista de variedades con un trabajador parte del universo laboral de su tiempo contribuyó también el mismo artista: su percepción de sí mismo y de su vocación como ejerciendo un don y una misión superior en la sociedad que ya satisfacían todas sus aspiraciones, naturalizarían las duras condiciones laborales y haría superflua la remuneración o, por lo menos, de menor importancia que para el resto de los trabajadores -lo mismo se aplicaría a médicos, docentes, bomberos, etc. a los que el sentido común atribuye aún en nuestros días el ejercicio algún tipo de sacerdocio. Estas circunstancias combinadas contribuyeron al tardío y complejo camino de la agremiación y a la pervivencia, hasta nuestros días, de situaciones heredadas de tiempos lejanos que todavía precarizan la situación laboral del actual artista de variedades. 


\section{Q Bibliografía}

"Anuario Estadístico de la Ciudad de Buenos Aires, Dirección General de Estadística Municipal, Imprenta El Centenario, 1913.

"Censo General de Población, Edificación, Comercio e Industrias de la ciudad de Buenos Aires, Compañía Sudamericana de Billetes de Banco, Buenos Aires, 1905.

»El Nacional

"Fray Mocho

» Kogan, G., C. Ulanovsky, S. Pelayes y M. López (2012). Los Productores. Historias de los empresarios teatrales argentinos de todos los tiempos, Buenos Aires: AADET.

"La Nación

»La Razón

》 Mauro, K. (2015). “La construcción identitaria de los actores: ¿trabajadores o militantes de la cultura?". En Actas del $12^{\circ}$ Congreso Nacional de Estudios del Trabajo: El trabajo en su laberinto. Viejos y nuevos desafíos, [en línea] Consultado el 15 de octubre de 2016 en <http://www.aset.org.ar/2015/ponencias/17_Mauro.pdf>.

》Mundo Argentino

»Orden del Día Policía de la Capital. República Argentina. Pedidos de Captura, volumen XXIX, año 1910, T. I.

»Prestigiácomo, R. (1995). En busca de la revista perdida. Entre monologuistas y bataclanas, Buenos Aires: Colihue.

» Seibel, B. (2011). Antología del Teatro Argentino. Desde los orígenes hasta la actualidad (1911 - 1920), Tomo 9, Buenos Aires: INT.

"Sosa Cordero, O. (1999). Historia de la Varieté en Buenos Aires 1900 - 1925, Buenos Aires: Corregidor.

"Szwarcer, C. (2014). La trayectoria de un destacado magnate de la noche e impulsor de diversas áreas de la industria y el comercio, con sede en la Argentina y proyección internacional (1900 - 1930), 11 de agosto [en línea] Consultado el 10 de marzo de 2016 en <http://blogs.monografias.com/estampas-de-buenos-aires/2014/o8/11/charles-seguin-un-asombroso-empresario-esplendor-y-ocasode-la-poderosa-south-american-tour/>. 